\title{
Editorial: the second special issue of the Journal of Hematopathology
}

\author{
J. Han van Krieken
}

Received: 12 February 2012 / Accepted: 12 February 2012 / Published online: 25 February 2012

(C) Springer-Verlag 2012

This first issue of the Journal of Hematopathology of 2012 is the second special issue. These yearly issues are created to bring reviews, teaching and new developments together on a specific topic that is part of the daily practice of hematopathologists. Clonality testing is a very good topic indeed. It is a test that is quite helpful in difficult cases, but also a test that is one of the more difficult to interpret. Each year, in February, there is a workshop in Nijmegen, the Netherlands, where colleagues from all over the world come to learn to use clonality testing in an optimal way. It is a real hands-on workshop in which most of the time is taken for the discussion of cases, both the pathology and the clonality data. Participants are only accepted when they come as a team of pathologist and molecular biologist and they have to bring at least one case that created problems. Where the first workshop was based on the cases of the course coordinators, in 2012, only two were, the others were brought by participants. Of course, the cases that the participants bring are challenging, sometimes for the pathologist, sometimes for the molecular biologist, often for both. By discussing these at the multiheaded microscope and with the actual molecular data with the combined expertise of the course directors and the participants, almost all cases can be solved, and in this process, a lot

J. H. van Krieken $(\triangle)$

Department of Pathology of the Radboud

University Nijmegen Medical Centre,

Nijmegen, The Netherlands

e-mail: J.vanKrieken@pathol.umcn.nl is learned; not only by the participants, but also by the teachers. But this is not new to experienced teachers: one learns more from teaching than from being a student. Based on the experiences in the workshop, this issue covers several aspects that are crucial for proper use of clonality testing.

The importance of close interaction of molecular biologist and pathologist brings about an important consequence: they need to communicate. This means that need to speak the same language, and preferably both are in the same laboratory. At the same time, we can observe a trend of concentration and specialisation. This development is in my opinion one of the great challenges for pathology today. How do we keep close contact with clinicians, technicians and molecular biologist, factors crucial for the optimal diagnosis, but at the same time are able to specialise? Few hematopathologists are in the situation that they work in an institution where there is sufficient specialisation or scale that they have everything at hand and have sufficient patient material to keep to hematopathology only. Most will have only a limited number of specialised techniques available and will not only do hematopathology but also cover other areas of pathology.

There are several developments which can be used to create good diagnoses. Digital pathology makes it easy to have expertise travelling. The increased use of molecular techniques makes molecular pathology available in a growing number of laboratories. New machines are cost-effective for fewer samples. But key to all the developments remains the expertise and communication skills of the hematopathologists. Hopefully, this issue will enable the reader to sharpen his or her skills in the area of clonality testing! 